Journal of Advanced Engineering Trends (JAET), Vol. 39, No. 1. January 2020

\title{
THE USE OF THE VOCABULARY OF CLIMATIC TREATMENTS FOR TRADITIONAL AND CONTEMPORARY ARCHITECTURE OBJECTIVES OF GREEN ARCHITECTURE PRINCIPLES IN EGYPT
}

\author{
Mohammed Azmi Ahmed ${ }^{1}$, Ashraf Abu El-Ayoun Abd El-Rahim², Rasha Maher Abdel- \\ Wahab $^{3}$ \\ ${ }^{1}$ Department of Architecture, Faculty of Engineering, Assiut University, Assiut, Egypt \\ ${ }^{2,3}$ Department of Architecture, Faculty of Engineering, Minia University, Minia, Egypt
}

\begin{abstract}
:-
This research paper is based on the methodology of monitoring, analysis and comparison of some international and local models and standing at a set of environmental treatment bases in both traditional and contemporary architecture and defining their characteristics as the vocabulary of climatic treatments and determining a mechanism for employing the vocabulary of traditional architecture. The principles of green architecture. The aim of the paper is to monitor the most important environmental treatments in both traditional and contemporary architecture and to define their function according to the principles of green architecture. It aims to monitor some of the contemporary models of the global, Arab and local buildings that used the vocabulary of traditional architecture according to the technology of green architecture, Of the environmental treatments according to their function and evolution from the traditional form to the technological form of contemporary architecture according to the comparative analytical method of analysis. The paper concludes with a set of conclusions and recommendations that draw the most important climatic treatments in the traditional architecture and how to employ them with advanced technological materials and technology in contemporary architecture according to the principles of green architecture to reach a building compatible with the local environment in Egypt.
\end{abstract}

Keywords: Traditional Architecture; Contemporary Architecture; Architectural Remedies Ancient and Modern 


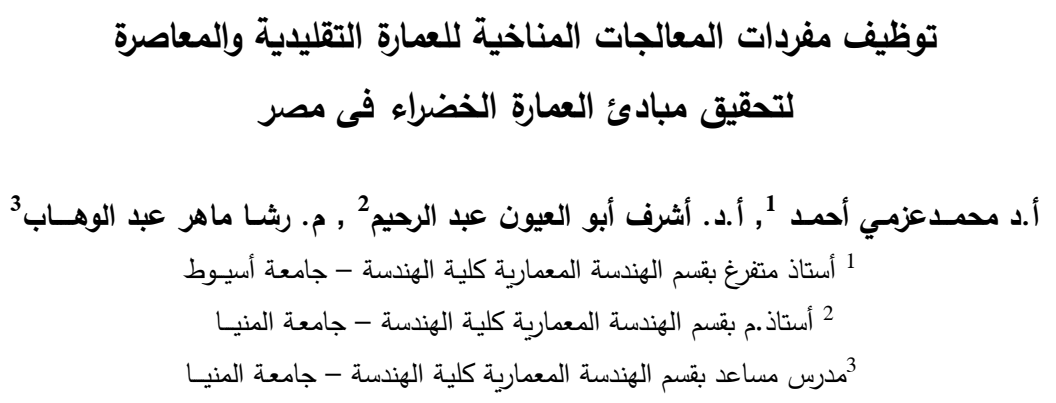

إن تنوع وتغير المعالجات المبيئية المناخية في العمارة الخضراء من أبرز السمات التي يمكن ملاحظتها في مبانيها والتي تعكس تغيرات

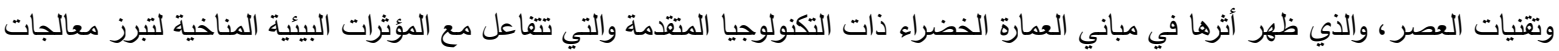
جديدة ذات تأثير مباشر على المبنى، وبسبب بعد المصمم عن استخدام المعالجات التقليدية الت يكانت تعمل على توفير تهوية وإضاءة طبيعية جيدة، كما أن التأثر بالعمارة الحديثة دون الاهتمام بمدى ملاءمتها للبيئة المناخية والاجتماعية المحيطة، أدى لزيادة معدل استهلاك الطاقة وزادت التأثيرات السلبية للبناءالحديث على البيئة فيصورة استتزاف مواردها. ويتجه البحث إلى دراسة مفردات المعالجات البيئية لمباني العمارة الخضراء بالعمارة التقليدية والعمارة المعاصرة المتقدمة وتحديدخصائصها والتغير ما بين الثكل التقليدي والثكل المعاصر التكنولوجي المتقدم للمباني، والمقارنة بين ما تحققه هذه المعالجات على مستوى المبنى التقليدي والمعاصر المتقدم وفق مبادئ العمارة الخضراء، والتعرف على أوجه التشابه والاختلاف بينهما لتحقيق مبنى متوافق مع البيئة المحيطة وفق مبادئ مائ ولئ العمارة الخضراء. تعتمد هذه الورقة البحثية على منهج الرصد والتحليل والمقارنة لبعض النماذج العالمية والمحلية والوقوف عند مجموعة من مرتكزات المعالجات البيئية سواء في العمارة التقليدية أو المعاصرة المتقدمة وتحديد سماتها كمفردات للمعالجات المناخية،وتحديد آلية لتوظيف مفردات معالجات العمارة التقليدية وادخالها في التصميم المعاصر لتحقيق الربط بين التقليدية والمعاصرة في ظل مبادئ العمارة الخضراء. تنتهى الورقة البحثية لمجموعة من النتائج والتوصيات التي تستخلص أهم المعالجات المناخية بالعمارة التقليدية وكيفية توظيفها بمواد

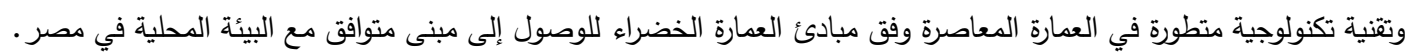
الكلمات الدالة: نردات معالجات العداة التقليية - مغردات معالجات العدارة المعاصرة- مبادئ العدارة الخضراء.

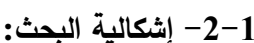

هناك محورين أساسين يثكلان الإشكالية البحثية لهذه

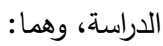
المحور الأول: التحليل لأثر العوامل البيئية على مفردات المعالجات المعمارية في العمارة الخضراء سواء كانت تقليدية محلية أو تكنولوجية متقدمة وذلك من خلال تحليل لمفردات العمارة التقليدية والمعاصرة وتحديد تاثيرها المباشر على تشكيل معالجات غلاف المبنى والذي يظهر تطور معالجات غلاف المبنى والذي يظهر تهري تطور المعالجات البيئية طبقاً لتطور العمارة من التقليدية وصولاً إلى لى لئي العمارة المعاصرة المتواكبة مع متطلبات وتكنولوجيا العصر . المحور الثاني: الاستنباط والمقارنة لخصائص مفردات المعالجات التقليدية والمعاصرة المتقدمة وتصنيف توافقها مع مبادئ

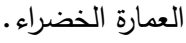
1-3-1 هدف البحث: تهدف الدراسة في هذه الورقة البحثية إلى تحقيق ما يلي:
1- مقدمة البحث: تعد العمارة التقليدية أساساً بيئياً وتراثياً وانطلاقة سليمة لتحديث العمارة المحلية في الاتجاه الصحيح، من هذا المنطلق تأتي المشكلة البحثية في دراسة إمكانية توظيف التقنيات التكنولوجية المتقدمة بالعمارة المعاصرة وفق المفردات المعمارية في العمارة

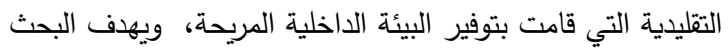
إلى التعرف علي العمارة التقليدية ودراسة مفرداتها المعمارية المكونة لها ومواد البناء وأساليب التتفيذ والتي لعبت دوراً هاماً في توفير البيئة

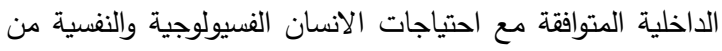
خلال استغلال الطاقات الطبيعية وبالتالي يمكن توفير الطاقة اللازمة للمبني عبر الوسائل الميكانيكية المستتفذة للطاقة، وقد أثر ذلك علي

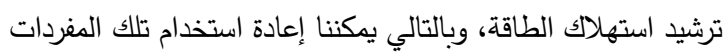
وتطوي رأسالييها لكي تحقق المعايير العالمية بم ايتوافق مع البيئة المحلية للمجتمعات العمرانية وبما يتتاسب مع مقومات المكان الطبيعية والاجتماعية والثقافية والاقتصادية. 
مما يتيح المجال للهواء البارد ليحل محلهم شكلاً مصدر من مصادر التهوية للسكان في المنزل ؛ شكل (3).

ج- المشربية: وهي عبارة عن ستائر خشبية ذات مقطع دائري تفصل بينها مسافات محددة ومنتظمة بشكل هندسي زخرفي دقيق وبالغ التعقيد وتعمل على ضبط الهواء والضوء إضافة لتوفيرها الخصوصية، وهي بارزة غالباًعن الجدار الخارجي حتى يسهل ونى

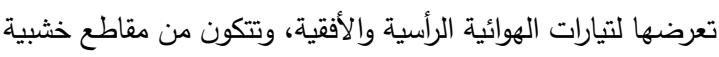
دائرية مترابطة بأشكال هندسية مختلفة كما في شكل (4)، وتعتبر المشربية من المغردات التقليدية الهامة، فهي تقوم بعدة وظائف في الفراغ الداخلي مناخية واقتصادية واجتماعية منها: ضبط مرور الضوء، وضبط تدفق مرور الهواء ورطوبته، وتحقيق الخصوصية والربط البصري بين الداخل والخارج في الوقت نفسهـ

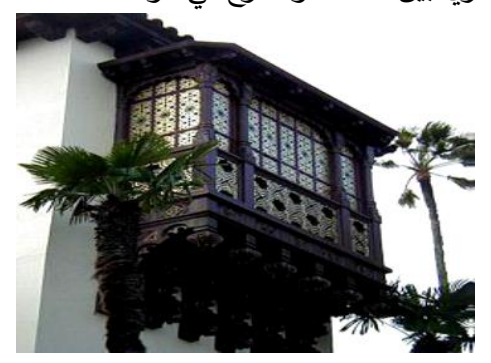

شكل رقم (4) المشربية بالعمارة التقليدية|1,5

ومن خلال إستعراض وتحليل إستخدامات مفردات معالجات النوافذ بأنئ والفتحات للعمارة التقليدية يمكن التوصل إلى إمكانية تحقيقالحفاظ على استهلاك الطاقة، والتهوية الجيدة، توفير الإضاءة الطبيعية داخل الفراغات بما يحقق التوافق مع مبادئ العمارة الخضراء. 2-2-2 مفردات معالجات الحوائط والأسقف: أ- الأقبية والقباب: تعتبر السقوف المقببة على شكل نصف كرة أو موات نصف اسطوانة يكون نصفها مظلل والنصف الآخر في الثمس كما تلقي الظلال على الأسطح المجاورة، وتعمل سطوحها المنحنية على لـى زيادة سرعة الهواء المار فوقها مما يعمل على خفض درجة درجة حرارة هذه السقوف9، كما في شكل رقم (5).
- رصد مفردات المعالجات البيئية التقليدية أوالمعاصرة المتقدمة من حيث الشكل والوظيفة ومدى توافقها مع مبادئ العمارة الخضراء. - تصنيف مفردات المعالجات البيئية التقليدية وتطورها طبقاً لوظيفتها وتطورها من الثكل التقليدي إلى الثكل التكنولوجي بالعمارة المعاصرة وفق المنهج التحليلي الاستتباطي المقارن. - رصد لبعض النماذج المعاصرة للمباني العالمية والعربية والمحلية التي استخدمت مفردات العمارة التقليدية وفق تقنية تكنولوجيا العمارة الخضراء لمعالجتها بيئياً.

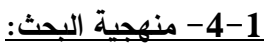
يعتمدالبحث عل ثثلاثة محاور هى كالتالى: الأول: المنهج النظري، والذي اعتمد على التعرف على رصدئ رأهم

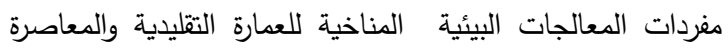
ووظائفها ومدى تحقيقها لمبادئ العمارة الخضراء... الثاني: المنهج التحليلي: من خلال تحليل عدة أمثلة معاصرة استمدت تصميمها من مفردات العمارة التقليدية. الثالث:المنهج الاستتباطي: ويهدف الى إستتباط أهم النتائج ووضع معند

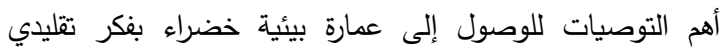
وتكنولوجيا معاصرة ومتوافقة مع مبادئ العمارة الخضراء. 2- مفردات المعالجات المناخية بالعمارة التقليدية التي أسست مبتيت لمفهوم العمارة الخضراء: توات تعد النتحات بأنواعها من أهم مفرداِت المعالجات لذا تميزت النوافذ والفتحات الخارجية بصغر مساحتها، تتخللها معالجات بالزخارف

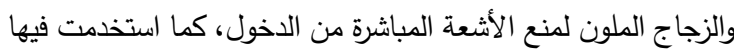
العناصر الآتية: - (القات - - القمريات والثمسيات:وهى اسم يطلق على الفتحات المقوسة التي تعلو عادةً النوافذ مباشرة مغطاة بالزجاج الملون في العمارة التقليدية، ويعتقد أن اسمها اشتق من الوظيفة التي تقوم بها وهي السماح لأشعة

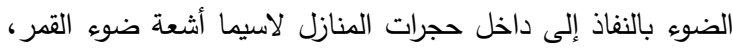
وتستخدم بشكل أساسي لتوفير الإضاءة لبعض المناطق دون تمرير الهواء الحار إلى داخل المنزل 4، كما في شكلى رقم ل (1) و و(2). ب- العمرية: بوهى عبارة عن فتحات صغيرة تستخدم للتهوية وتكون علنالأغلب على شكل دوائر أومضلعات وتقع في السقوف وفي القباب

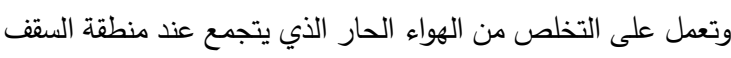

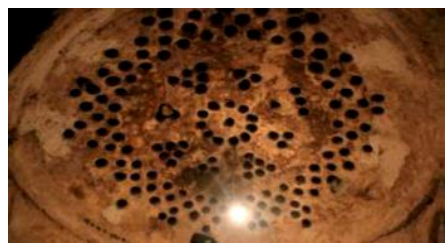

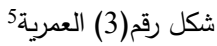

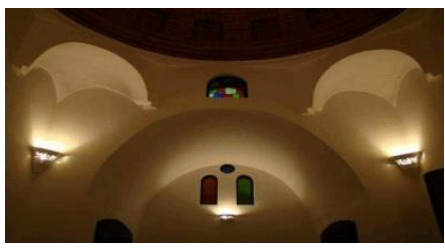

شكل رقم (2) الثمسيات1

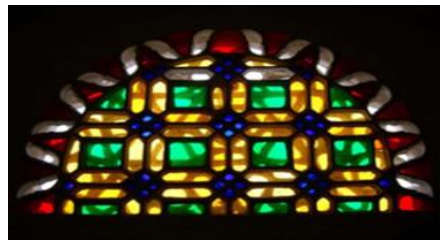

شكل رقم(1) القمرية5 

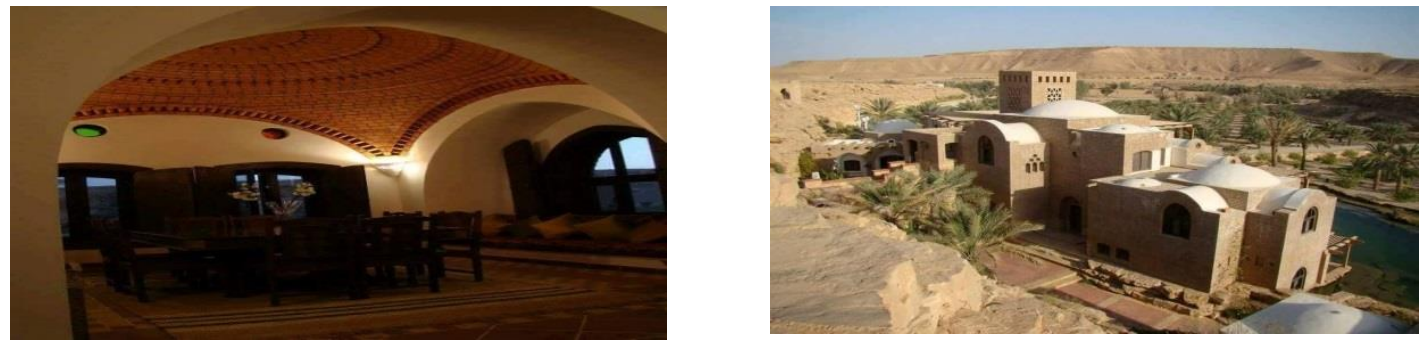

شكل رقم (5) الأسقف المقببة في العمارة التقليدية(1)
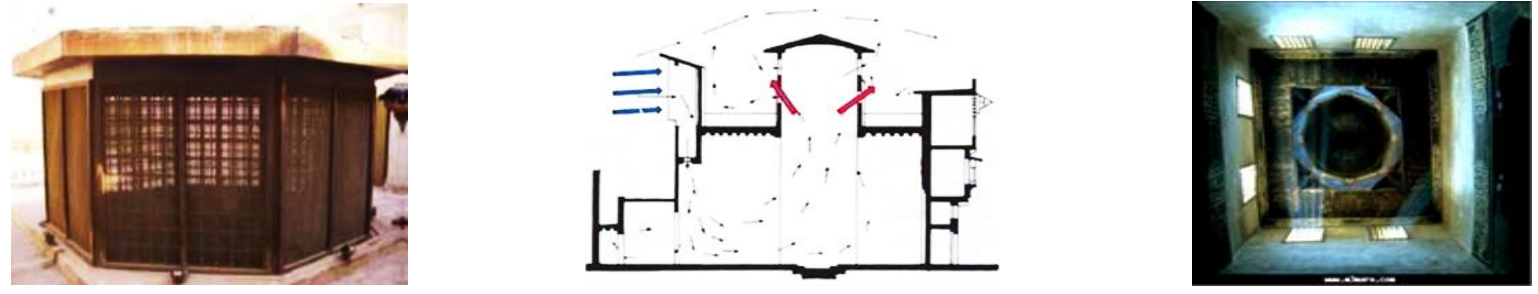

شكل رقم (6) شخشيخة من الخشب لإنارة القاعة6

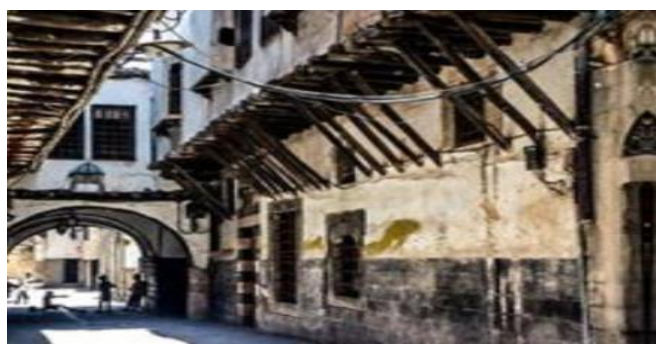

شكل رقم (8)|ستخدام البروزات وكاسرات الشمس5

القبابوالقبوات والألوان والملمس للحوائط بما يحقق التوافق مع مبادئ العمارة الخضراء.

-3- البروزات وكاسرات الثمس: ومنها الرفرفو هو عبارة عن بروازت من الطين والخشب محمولة على كوابيل شكل رقم (8)،

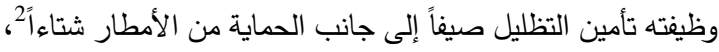
ولأقصى تأثير حراري للكاسرات يجب وضعها خارج الفتحات الزجاجية، وتتنوع الكاسرات الثمسية ما بين الرأسية والأفقية، ويمكن

$$
\text { أن تكون متحركة أو ثابتة'9. }
$$

ومن خلال إستعراض وتحليل إستخدامات مفردات

البروزات وكاسرات الثمس للعمارة التقليدية فإنه يمكن التوصل الىى إمكانية تحقيق الحفاظ على الطاقة، وتحسين الراحة الحرارية داخل الفراغات والتشكيل البصري عن طريق توفير الظلال للواجهات بما يحقق التوافق مع مبادئ العمارة الخضراء.

2-2- الأفنية الداخلية والملاقف (أبراج الرياح) والنافورة: الفناء الداخلي:وهو مساحة مفتوحة محاطة بحوائط تقع داخل أوخارج المبنى وتطل عليها بعض نوافذ الحجرات ويستخدم كعنصر

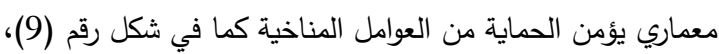
ويساعد في توفير الإضاءة والتهوية الطبيعية واستخدام الطاقة الطبيعية وخفض الطاقة المستهلكة.

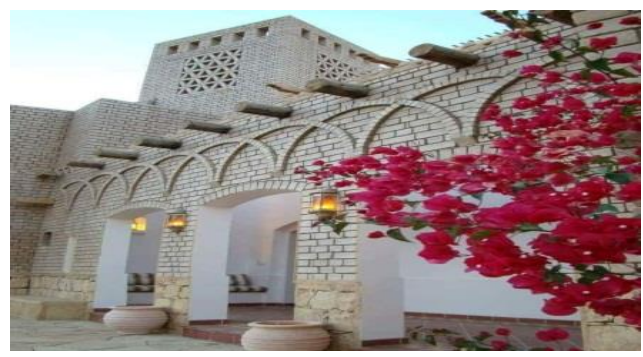

شكل رقم (7) المواد والملمس1

ج- الحوائط المزدوجة: تم استخدام الجدران ذات السماكات العالية، وذلك للتغلب على خاصية المدى الحراري الكبير الذي تتميز به الهن داته المناطق الحارة والجافة من المنطقة العربية، حيث تحجز فيما بينها

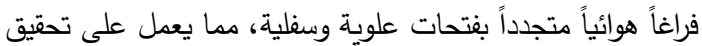

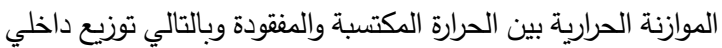

$$
\text { منتظم للحرارة داخل المبنى 2. }
$$

دـ الإنشاء والمواد والملمس:تظهر العناصر الإنشائية في العمارة

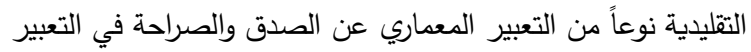
والإنثاء،لاستعمالها مواد البناء الطبيعية كالطوب والأحجار والخشب لونب وغيرها من العناصرالطبيعية المتوفرة محلياً شكل (7)، والمستخدمة في البناء حسب صفاتهاوامكانياتها الإنثائية، ويتم التحكم في الانتقال الحراري بين البيئة الخارجية والوسط الداخلي للمبنى في العمارة

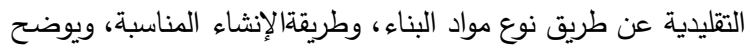
الملمس طبيعة الأسطح المعمارية المكونة للمبنى وظيفياً وفنياً(10).

ومن خلال إستعراض وتحليل إستخدامات مفردات الحوائط والأسقف للعمارة التقليدية فإنه يمكن التوصل الى إمكانية تحقيق الحفاظ على إلى معلى

الطاقة، والراحة

الحرارية داخل الفراغات وكذا الراحة البصرية من خلال تنوع أثكال 
ب- الملقف:من الحلول الجيدة للتهوية الطبيعية في العمارة التقليدية استعمال الملاقف الهوائية، وقد انتشر استعمال الملاقف الهوائية في

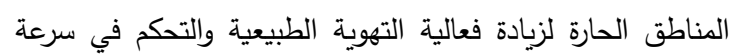

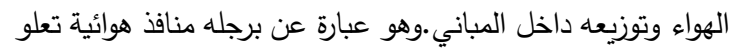

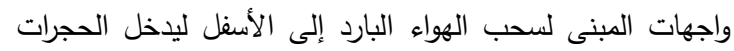

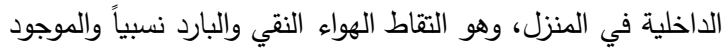

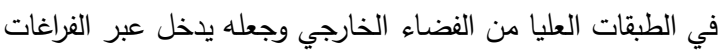
الداخلية بواسطة محرك هوائي رئيسي محاط بجدار سميك يتميز بسعة حرارية عالية، قد يكون الملقف الهوائي ثابتا لتوجيه وفي لهي

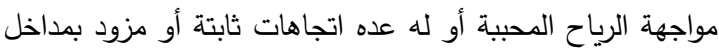

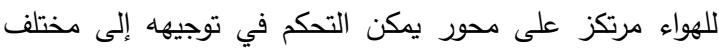

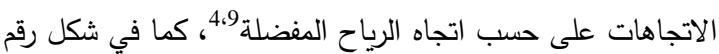

ج- النافورة: وهى عادة ما توضع في وسط الفناء الخاص بالمنزل ويقصد بالنافورة إكساب الفناء المظهر الجمالي وامتزاج الهواء بالماء وترطيبه ومن ثم انتقاله إلى الفراغات الداخلية، كما بالثكل رقم
يعمل الفناء كخزان للبرودة، يقوم بتخزين الهواء البارد ليلاً

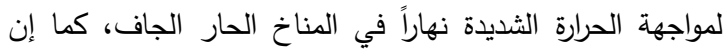

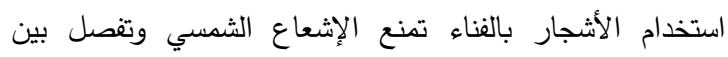

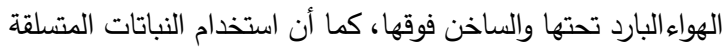
لعزل جدران الفناء من الثعاع الثمسي وإعطاء الفرصة لاكتسابها فيفصل الثتاء عندما النباتات تفقد أوراقها، ومن المفيد استخدام نوافير الماء المظللة ويفضل أن تكون متحركة لزيادة الترطيب بالرذاذ ومنع أداء الماء الساكن كسطح عاكس 1 .

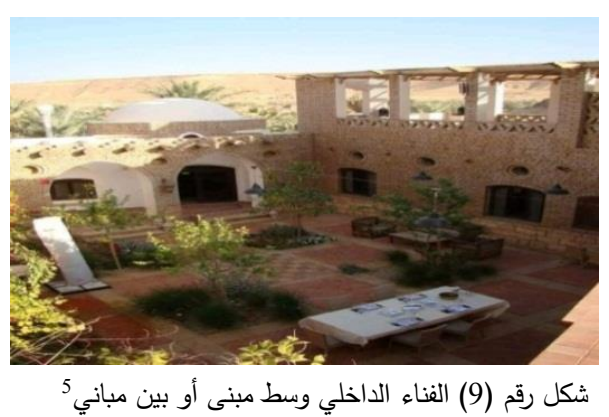

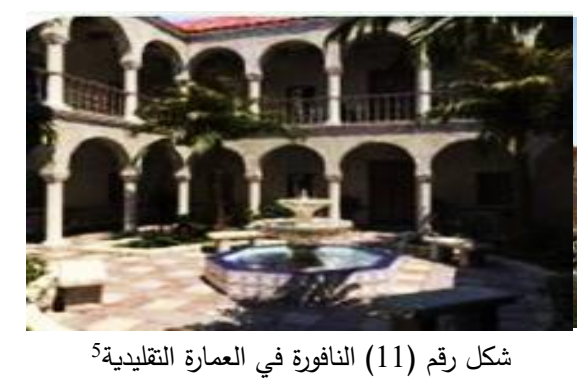

3- مفردات المعالجات المناخية بالعمارة المعاصرة المتقدمة التي أسست لمفهوم العمارة الخضراء أ-1-3 مفردات معالجات النوافذ الفتحات الخارحية:

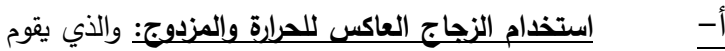
بعكس الحرارة والإستفادة من الإضاءة الطبيعية، ويتم استخدام النوافذ ذات الزجاج المزدوج أومتعدد الطبقات فتسمح بدخول ضوه ألثعة

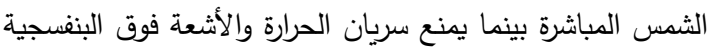

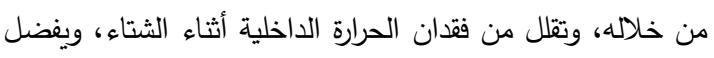

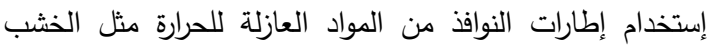

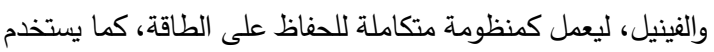
في بعض الأحيان نظام حساسات الطقس الموجود على الغلاف

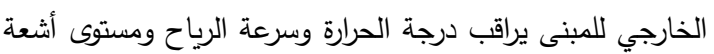

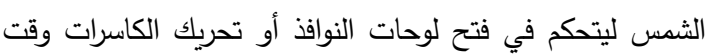

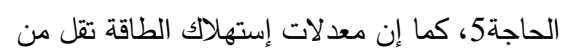

ومن خلال إستعراض وتحليل إستخدامات مفردات الأفنية الداخلية

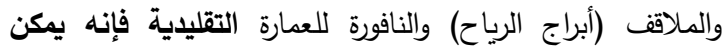
التوصل الى إمكانية تحقيق الحفاظ على الطاقة والتكيف مع المناخ من خلال تحقيق تهوية جيدة داخل المبنى وتحسين الراحة الحرارية

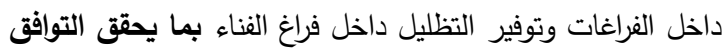
مع مبادئ العمارة الخضراء. ونستنتج مما سبق أنالأسس البيئية التي اعتمدت عليها العمارة التقليدية لتحقيق جودة الإضاءة والتهوية الطبيعية والراحة الحرارية في مبانيهم قامت على مبدأ خلق تيارات من الهواء الطبيعي عن طريق توفير مناطق ضغط متباينة في المبنى بمساعدة المفردات التي تحقق تقليل شدة الإشعاع الشمسي وتوفير الإضاءة الطبيعية

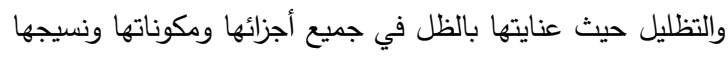
العمراني بالاضافة لتركة لمسة جمالية فالاختلاف بين المساحات

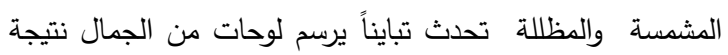

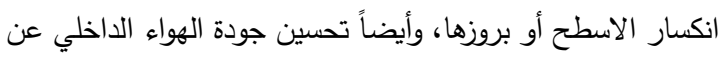
طريق ترطيب الهواء بالعناصر المائية والخضراء. 
شكل (14) يوضح مباني فرانكجيري تكنولوجيا تركيب النوافذ6

ومن خلال إستعراض وتحليل إستخدامات مفردات النوافذ الفتحات الخارجية للعمارة المعاصرة المتقدمة فإنه يمكن التوصل المى إمكانية تحقيق هذه الفتحات الحفاظ على الطاقة، بينما تعمل الكواسر

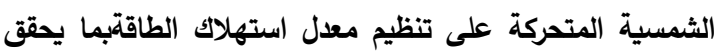
التوافق مع مبادئ العمارة الخضراء.

2-3-3فردات معالجات الحوائط والأسقف: ومما سبق نستتتج أن هناك ارتباط بين العمارة التقليدية والمعاصرة

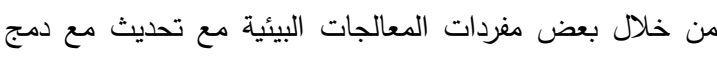

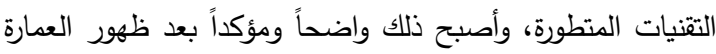
الخضراء وتقنياتها التي أصبحت هي عنصر الارتباط بين الأصالة

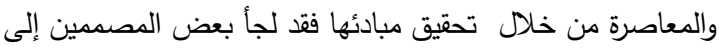
نقل المفردات التقليدية ووضعها في مبانيهج بتعديلات طفيفة، ولجأ آخرون إلى النقل عنها مع إجراء تغيرات شكلية في النسب أو الثكل أومواد لإنثاء، بينما استفاد العديد منهم من فهم المتطلبات البيئية في تصميم المغردات التقليدية وترجمتها في تصاميم حديثة مبتكرة والاستفادة من التقنيات المتطورة، ويتم في الجدول التالي (1)عمل وتردي دراسة مقارنة لتوضيح الارتباط والتطور بين العمارة التقليدية والمعاصرة من خلال عرض لبعض الأمثلة المعاصرة مع توضيح مدى تحقيق المبادئ المحققة في كل تجربة.

4-دراسة تحليلية مقارنة لتطور مفردات المعالجات البيئية في العمارة التقليدية من خلال بعض التجارب المعاصرة: نتيجة لظهور بعض النماذج المعمارية لمباني معاصرة متأثرة في معالجاتها بالعمارة التقليدية في الآونة الأخيرة من حيث إعادة استخدام بعض مفردات العمارة التقليدية بطريقة حديثة وإعادة توظيفها في تلك المباني المعاصرة، فقد تم تناول تلك الظاهرة بالرصد والتحليل والدراسة بإعتبارها أحد أهداف البحث، حيث تم تجميع البيانات من

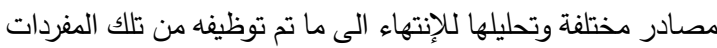
التقليدية بالعمارة المعاصرة طبقا لما تضممنته الدراسة البحثية

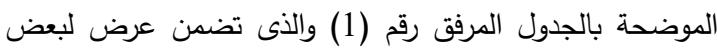

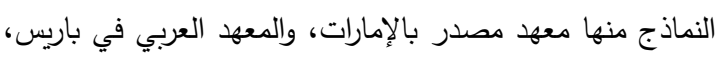

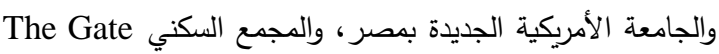

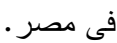

خلال تركيب نوافذ ثنائية وثلاثية الألواح الزجاجية وعوارض زجاجية ذات فواصل حرارية شكل (12)، فضلاً عن إستخدام

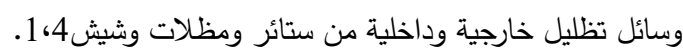

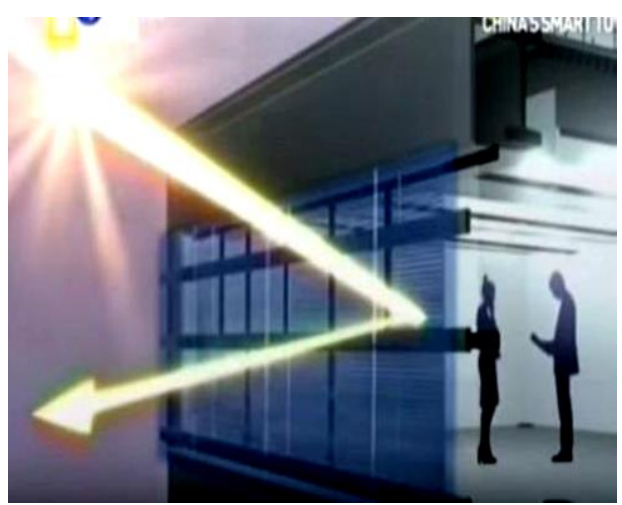

شكل رقم (12) استخدام الزجاج العاكس والمزدوج بالواجهات4

ب- كاسرات الشمس التكنولوحية:

استخدام كاسرات الثمس التكنولوجية تساعد في تحديد مستوى أشعة الثمس النافذة للمبنى وسرعة الرياح وبالتالي تعتبر كمنظم معدل يحقق حفظ الطاقة، إلى جانب خلق التباين والظلال على الواجهات، كما شكل (13)/ ويظهر ذلك في مباني فرانكجيري من خلال زجاج هذه النوافذ بواسطة تكنولوجيا التحكم في تركيب الثبابيك وحركتها الأفقية والرأسية شكل رقم (14)، ومن خلال تكنولوجيا تشطيبات الواجهات واستخدام أسطح شفافة تمكن من السيطرة جزئيًاعلى الطاقة 8

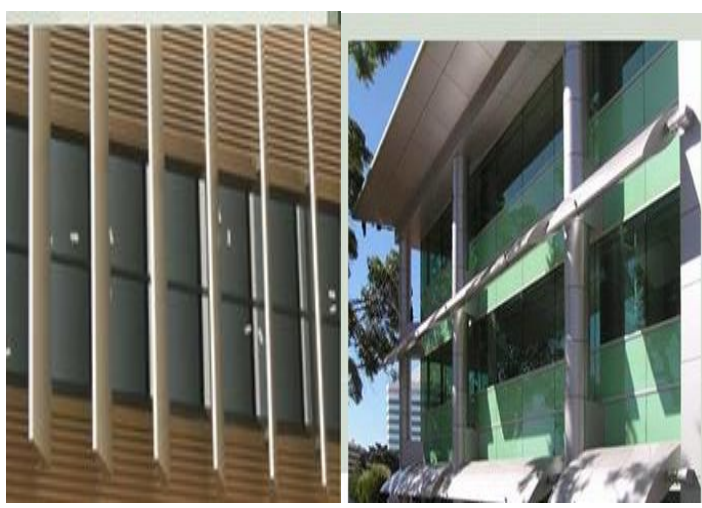

شكل رقم (13) استخدام الكاسرات الأفقية والرأسية المتحركة

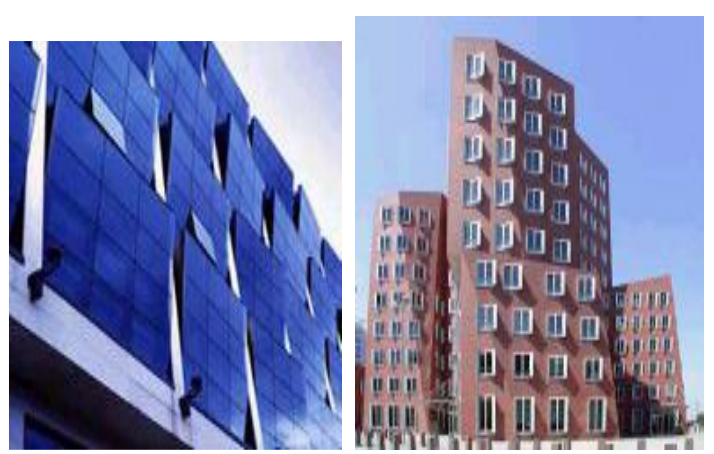




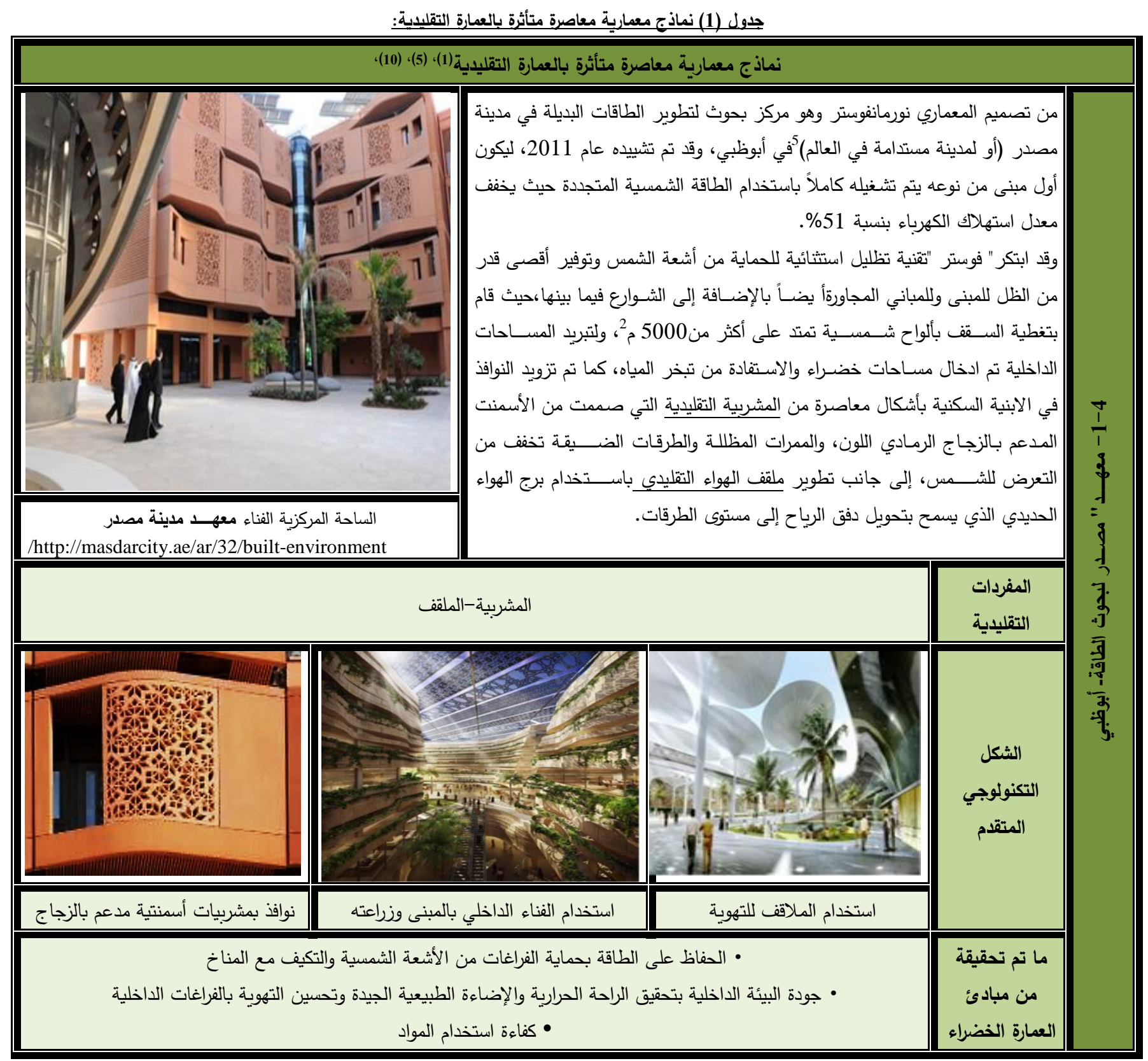

من إعداد الباحثة (بتصرف)5 
تابع جدول (1) نماذج معمارية معاصرة متأثرة بالعمارة التقليدية:

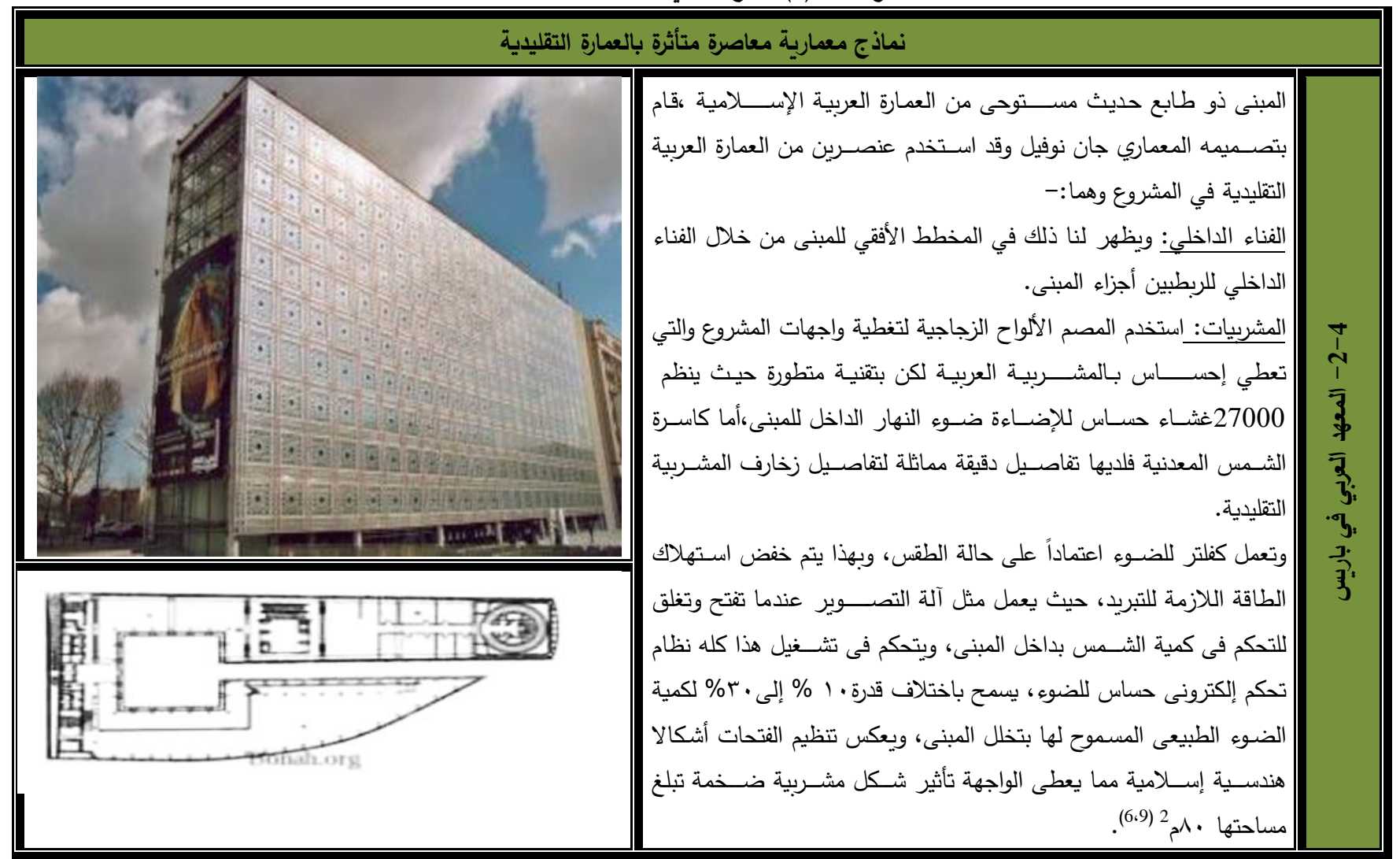

www.castel4a.com/showthread.php>2-3-2013

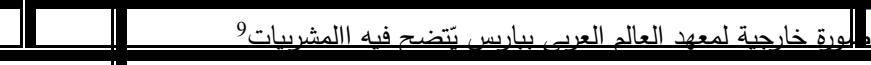

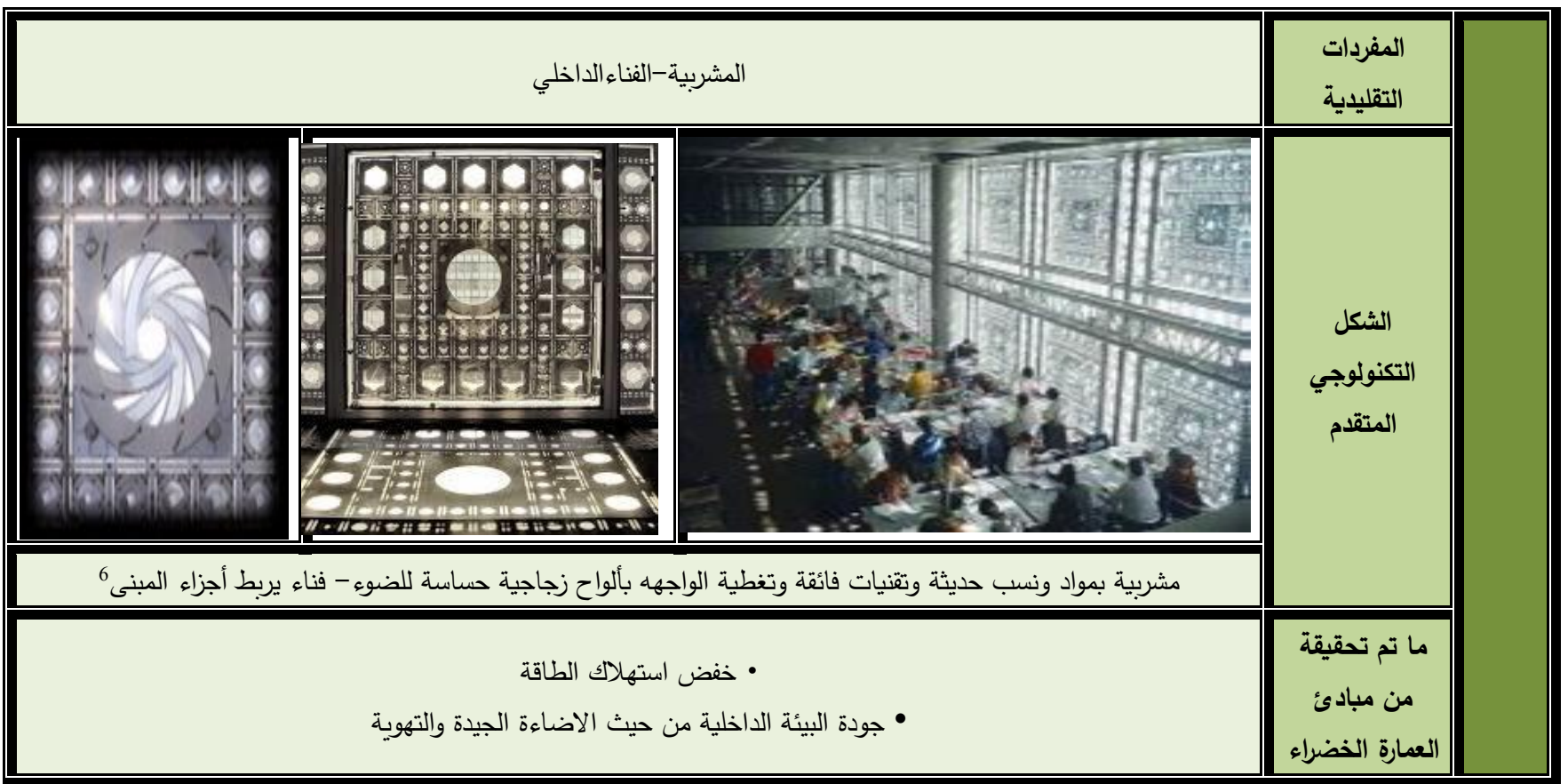

من إعداد الباحثة

الوانها، إلى جانب قابلية تركيبها على الأســــحح المنحنية والدائرية بما يحقق التوافق مع مبادئ العمارة الخضراء. ومما سـبق نسـتنتج أن هناك ارتباط بين العمارة التقليدية والمعاصــرة من خلال بعض مفردات المعالجات البيئية مع تحديث ليث مع دمج التقنيات المتطورة، وأصبح ذلك واضحاً ومؤكداً بعد ظهور
ومن خلال إســـتعراض وتحليل إســـتخدامات مفردات اســـتخدام

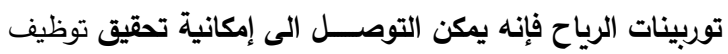

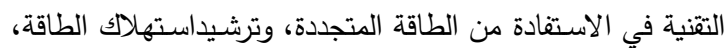
كما إن اســتخدام الخلايا الضــوئية (فوتولتايك PV) يحقق مرونة شـكل غلاف المبنى نظراً لاختلاف شــفافية وحدات الخلايا وتعدد المديه 
نتيجة لظهور بعض النماذج المعمارية لمباني معاصـــرة

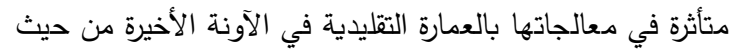

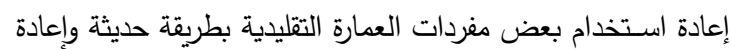
توظيفها في تلك المباني المعاصـــرة، فقد تم تتاول تلك الظـاهرة

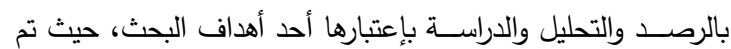

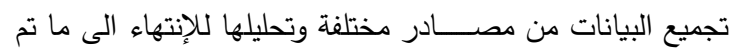

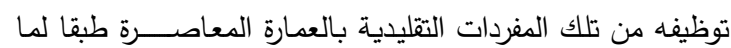
تضممنته الدراسة البحثية الموضحة بالجدول المرفق رقم (1) والذى بأى

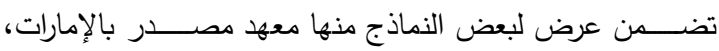

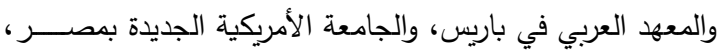

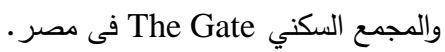

العمارة الخضـراء وتقنياتها التي أصبحت هي عنصـر الارتباط بين

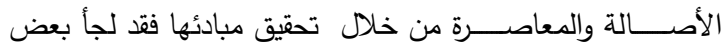

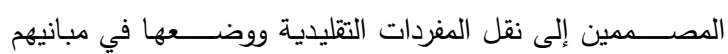
بتعديلات طفيفة، ولجأ آخرون إلى النقل عنها مع إجراء تغيرات

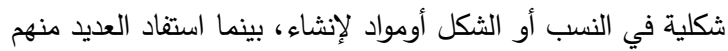

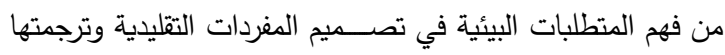
في تصــاميم حديثة مبتكرة والاســتفادة من التقنيات المتطورة، ويتم

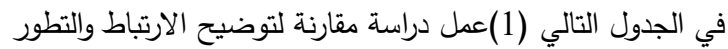
بين العمارة التقليدية والمعاصــــرة من خلال عرض لبعض لهض الأمثلة المعاصرة مع توضيح مدى تحقيق المبادئ المحققة في كل تجربة.

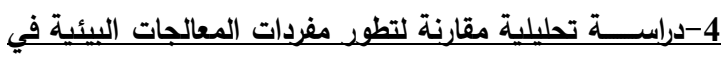
العمارة التقليدية من خلال بعض التجارب المعاصرة:

تابع جدول (1) نماذج معمارية معاصرة متأثرة بالعمارة التقليدية:

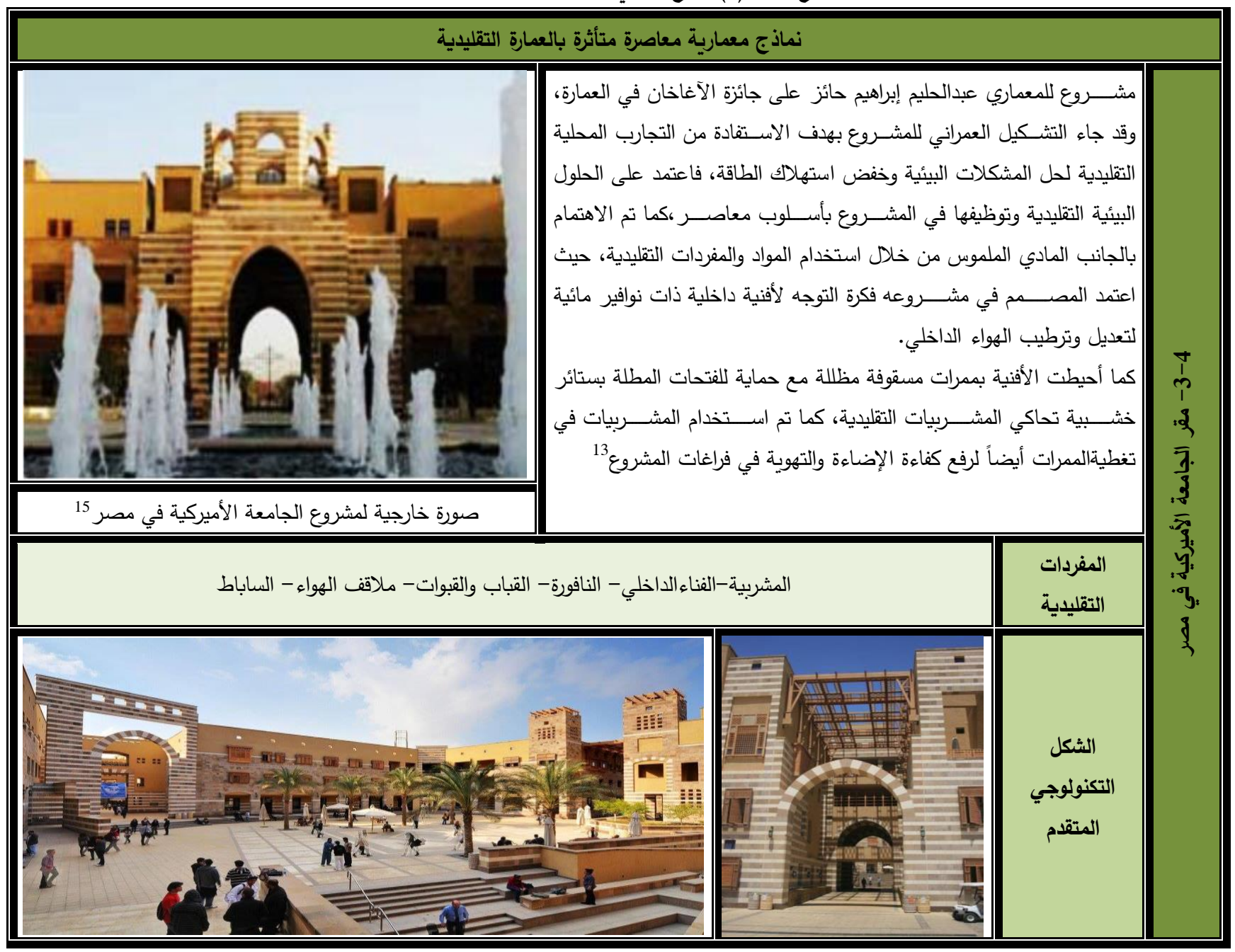



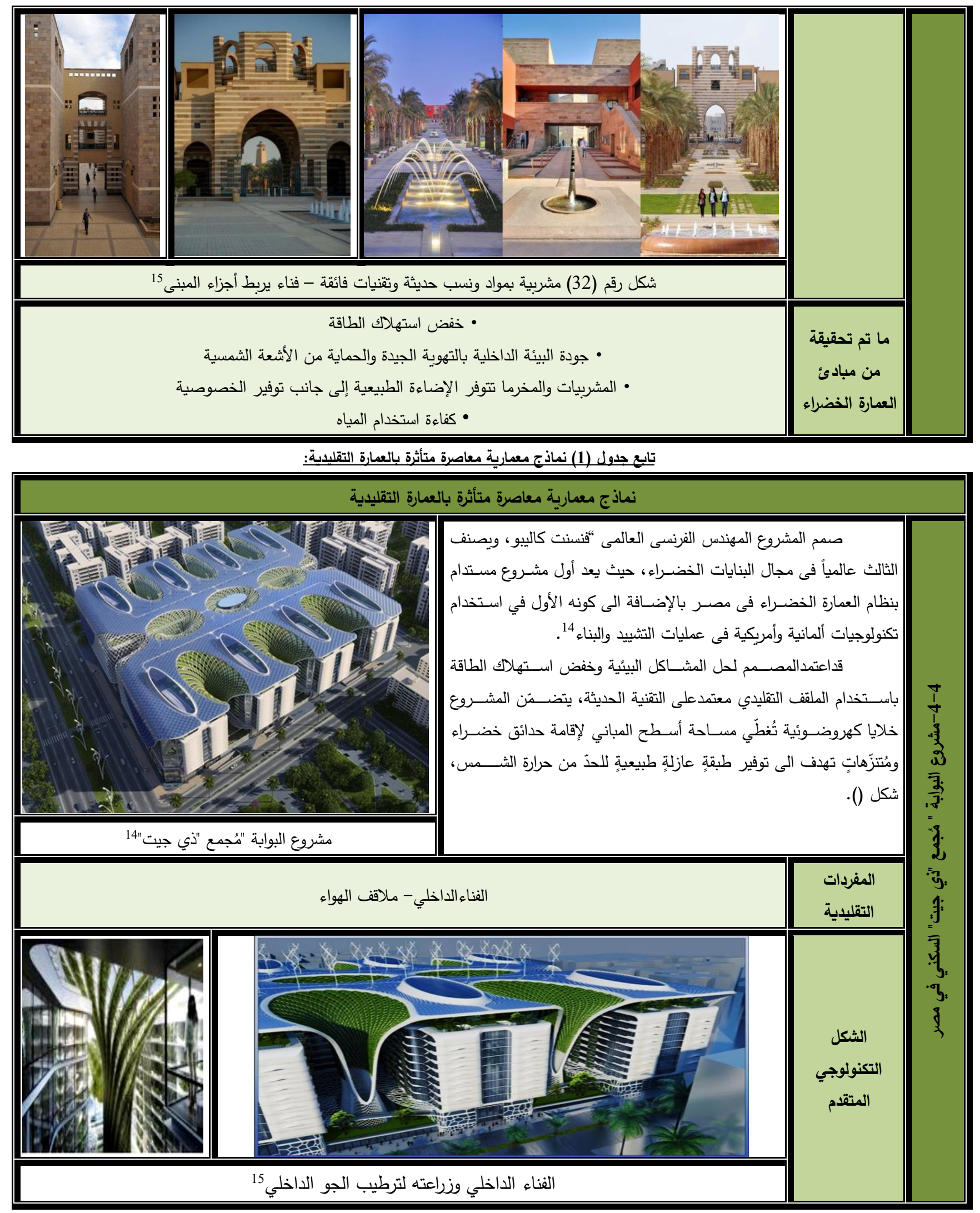


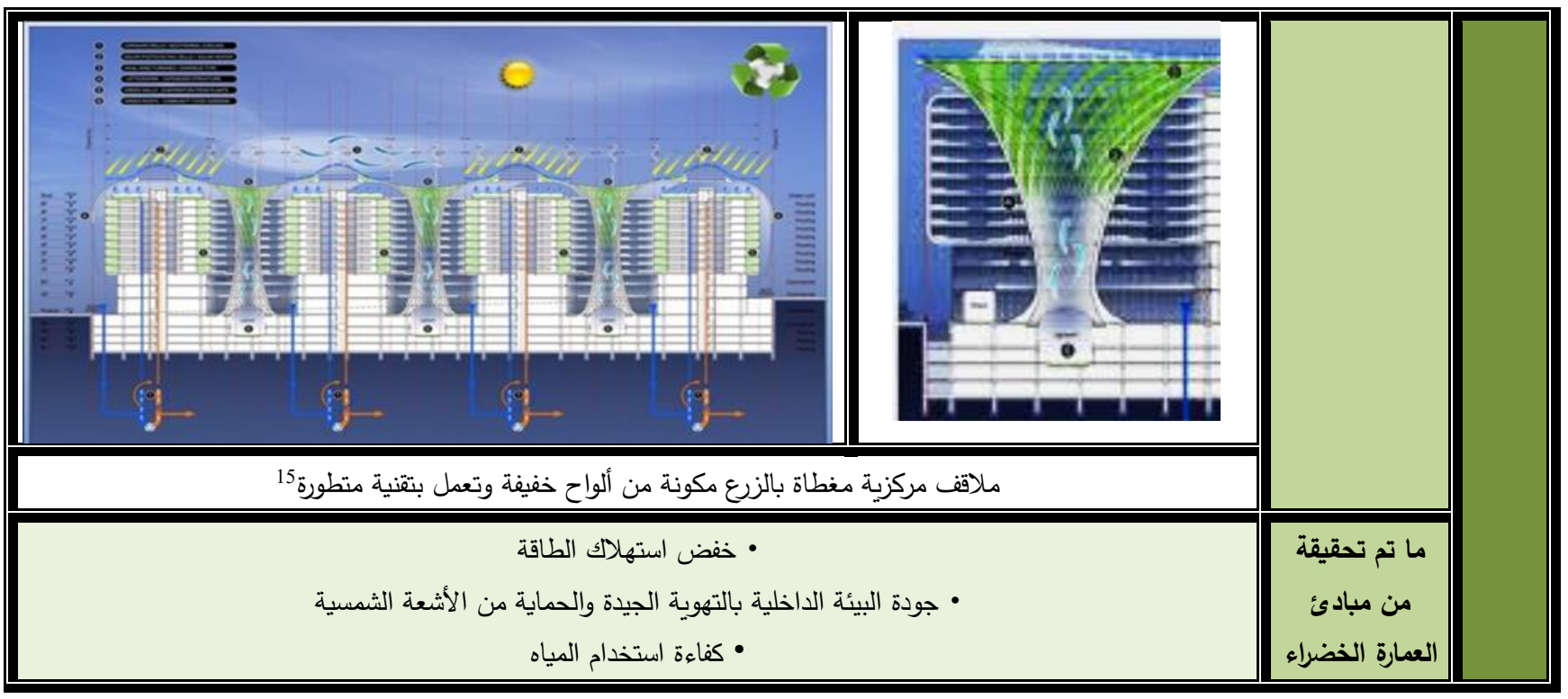

نتيجة لعرض النماذج المعمارية السـابقة وتوضـيـح إعادة

استخدام وتوظيف بعض مفردات العمارة التقليدية بطريقة حديثة في

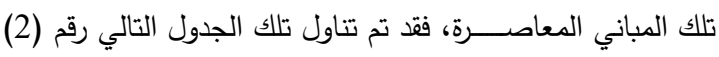

الرصــــــ والتحليل والمقارنة لمفردات المعالجات المعمارية للعمارة

التقليدية والمعاصـرةودراسـة لتطور هذه المفردرات المعمارية وكيفية

توظيفها.

ومن خلال الجدول السـابق عرضــه رقم (1) وما تضــنه

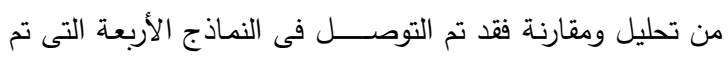

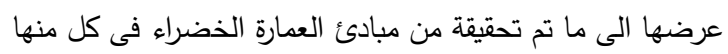

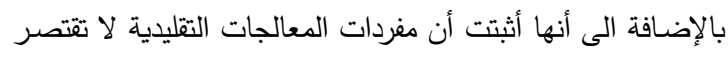

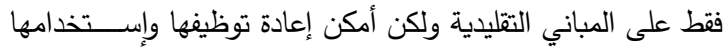
بواسطة التكنولوجيا المتقدمة في المباني المعاصرة.

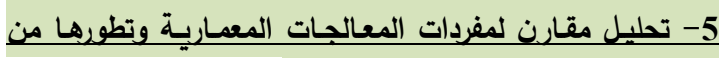
العمارة التقليدية إلى المعاصرة المتقدمة:

جدول (2)تحليل مقارن لمفردات المعالجات المعمارية وتطورها من العمارة التقليدية إلى المعاصرة المتقدمة:

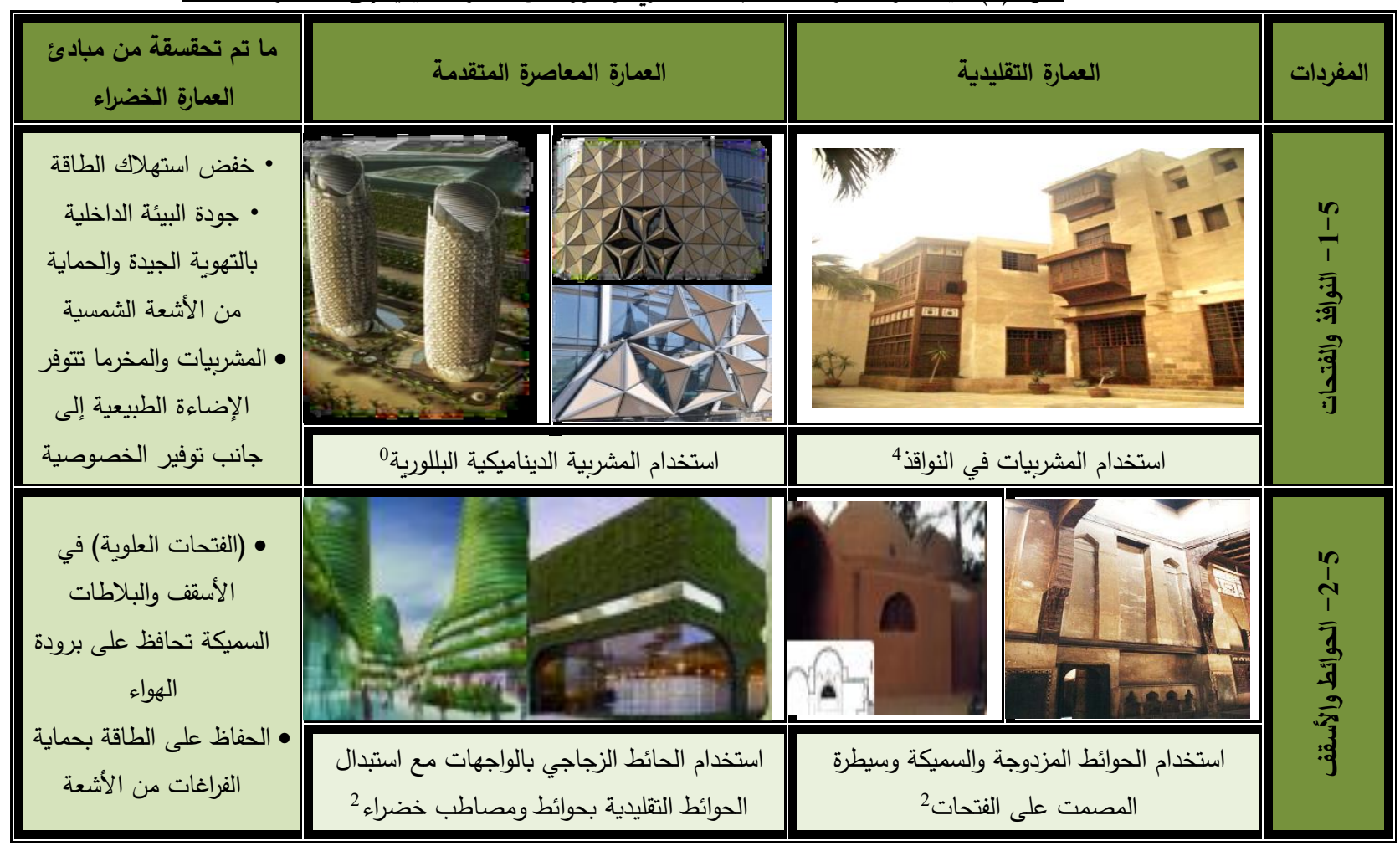




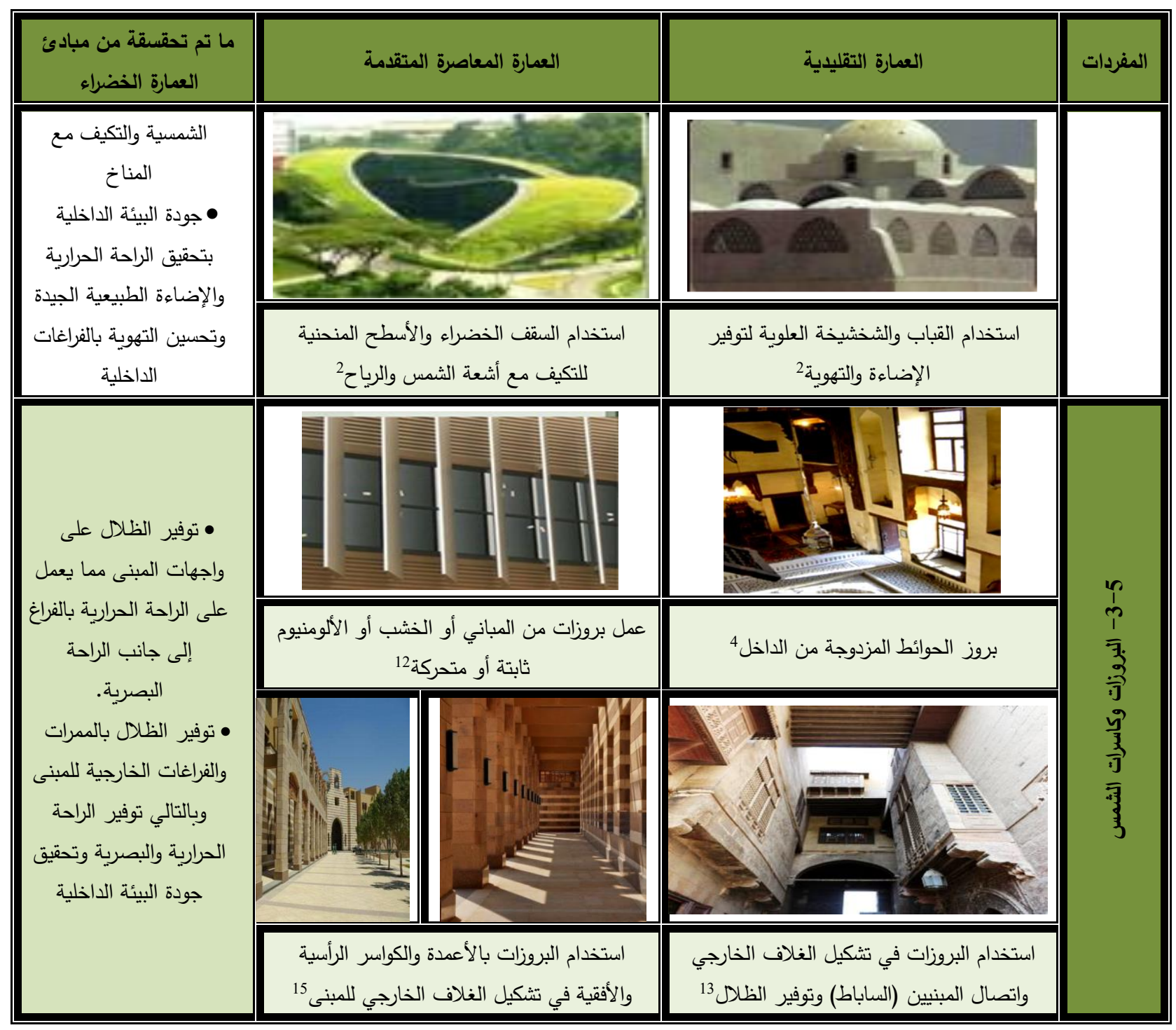

تابع جدول (2) تحليل مقارن لمفردات المعالجات المعمارية وتظورها من العمارة التقليدية إلى المعاصرة المتقدمة:

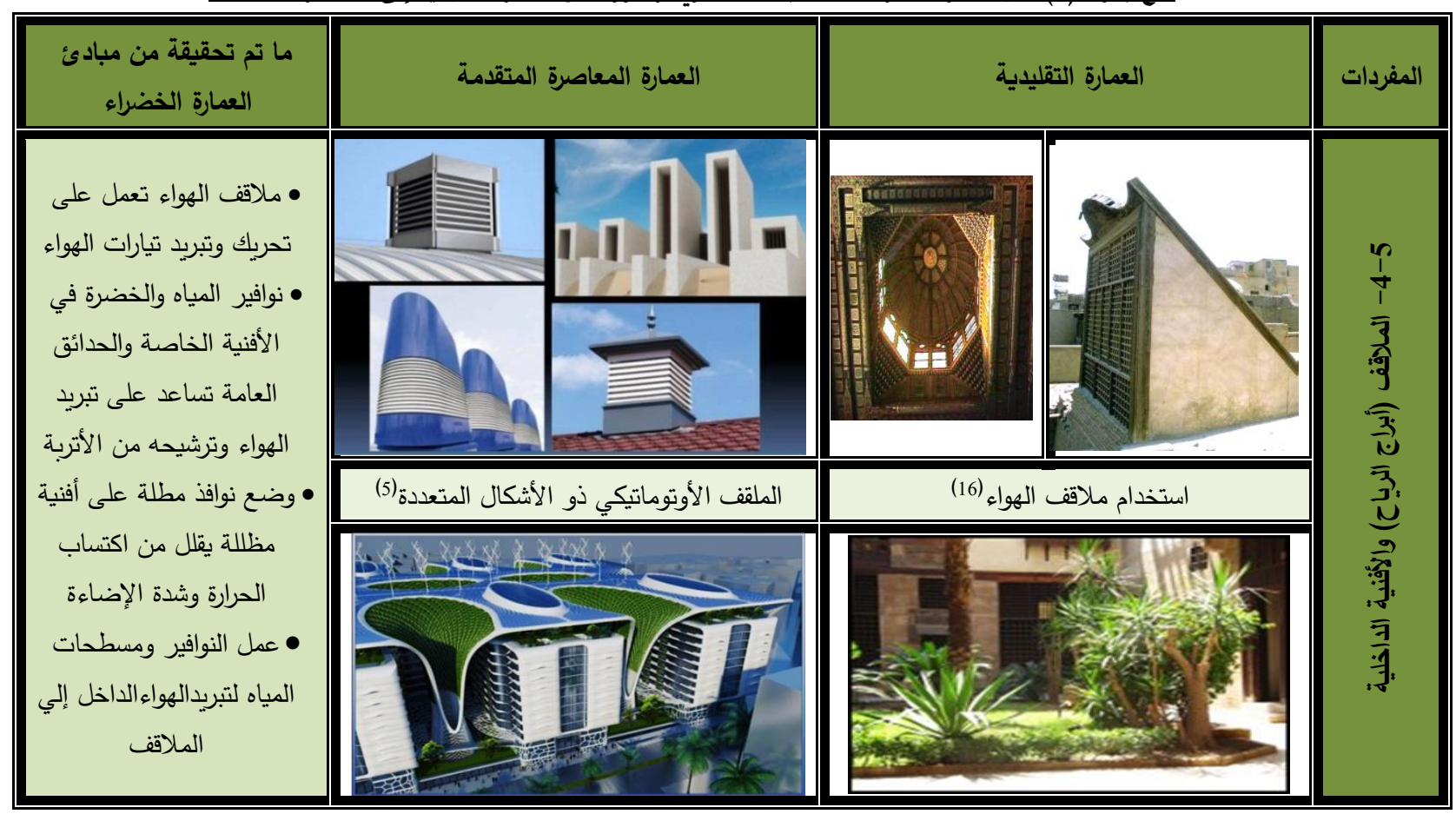




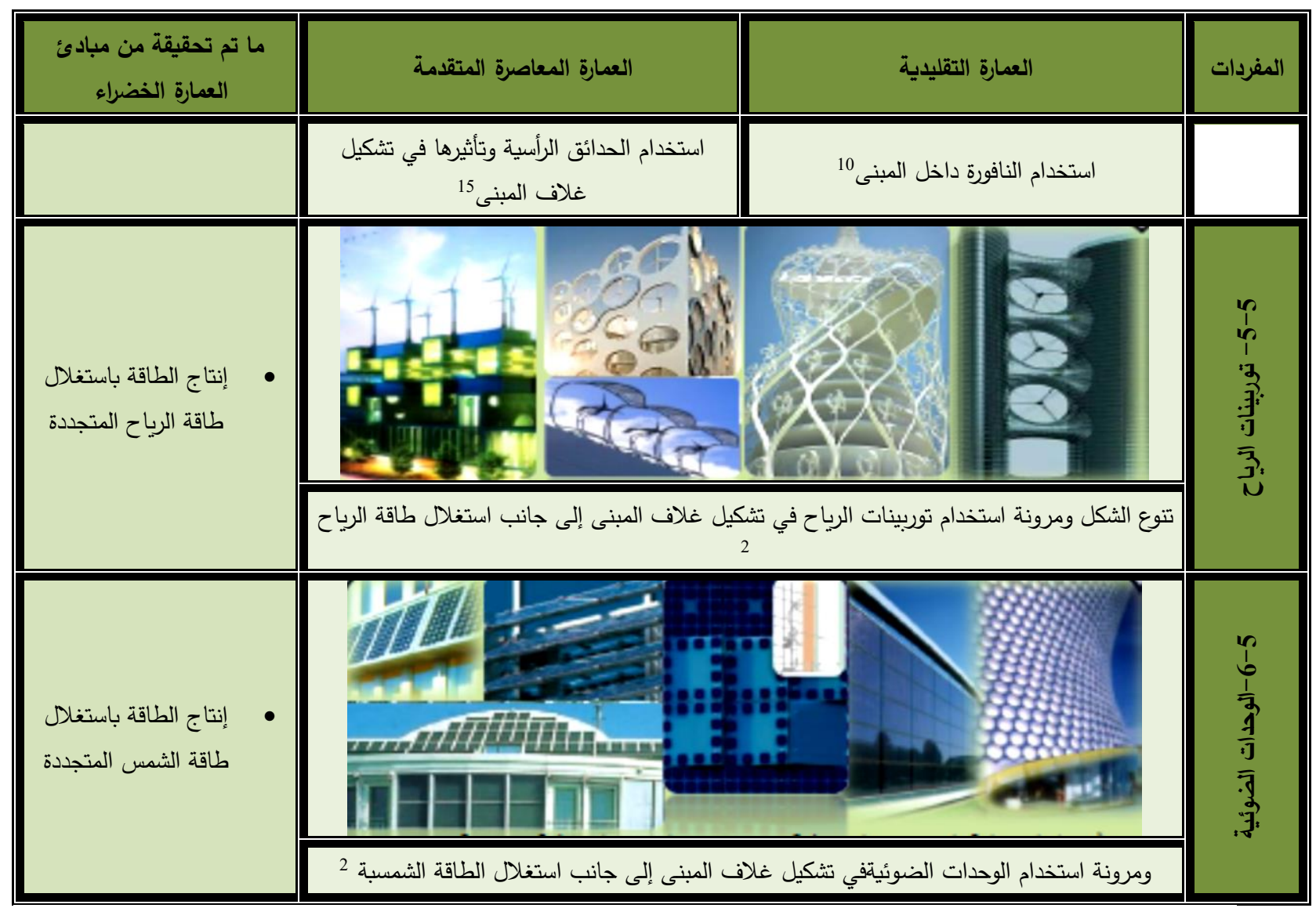

التقنيات الحديثة التي تعتمد على توظيف الأنظمة عالية الكفاءة وأنظمة التحكم في المباني لتقليل الفاقد

$$
\text { في أحمال التبريد والتدفئة والتحكم الكلي بها. }
$$

6-التحليل المقارن لنوظيف مفردات المعالجات المناخية المعمارية

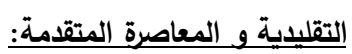

ومن خلال عرض المفردات المعمارية السـابقة وتوضـيح

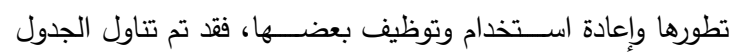

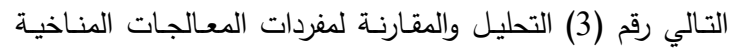

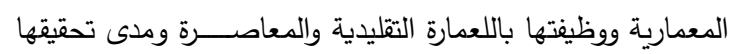

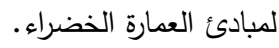

ومن خلال ما تضمنه الجدول السابق من تحليل ومقارنه فإنه يمكن

$$
\text { أن نستتتج منه ما يلي: }
$$

• ترشيد استهلاك الطاقة من خلال توظيف التقنيات الحديثة

في تحقيق عناصـر المبنى المختلفة العناصـر الخارجيةالغلاف الخارجي - العناصــــر الداخلية) لوظيفتها بكفاءة

$$
\text { وفعالية عالية. }
$$

• توليد الطاقة من مصــــادر متجددة وإدماج أنظمة توليد

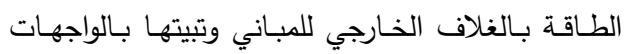

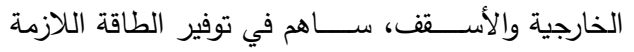

للتشـغيل بنسـبة كبيرة تصـل في بعض منها إلى الإكتفاء

الذاتي.

$$
\text { • تحقيق مستويات جيدة من التهوية والتبريد والتدفئة من }
$$

حدول (3)مدى تحقيق مفردات المعالجات التقليدية والمعاصرة للعوامل البيئية المناخية.

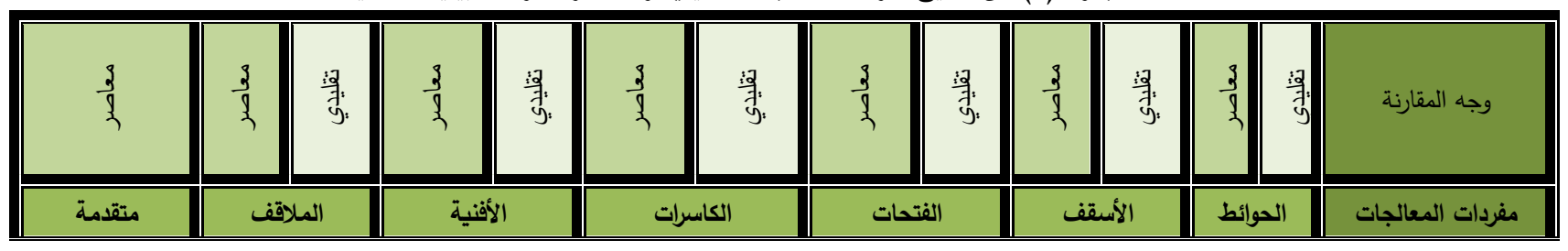




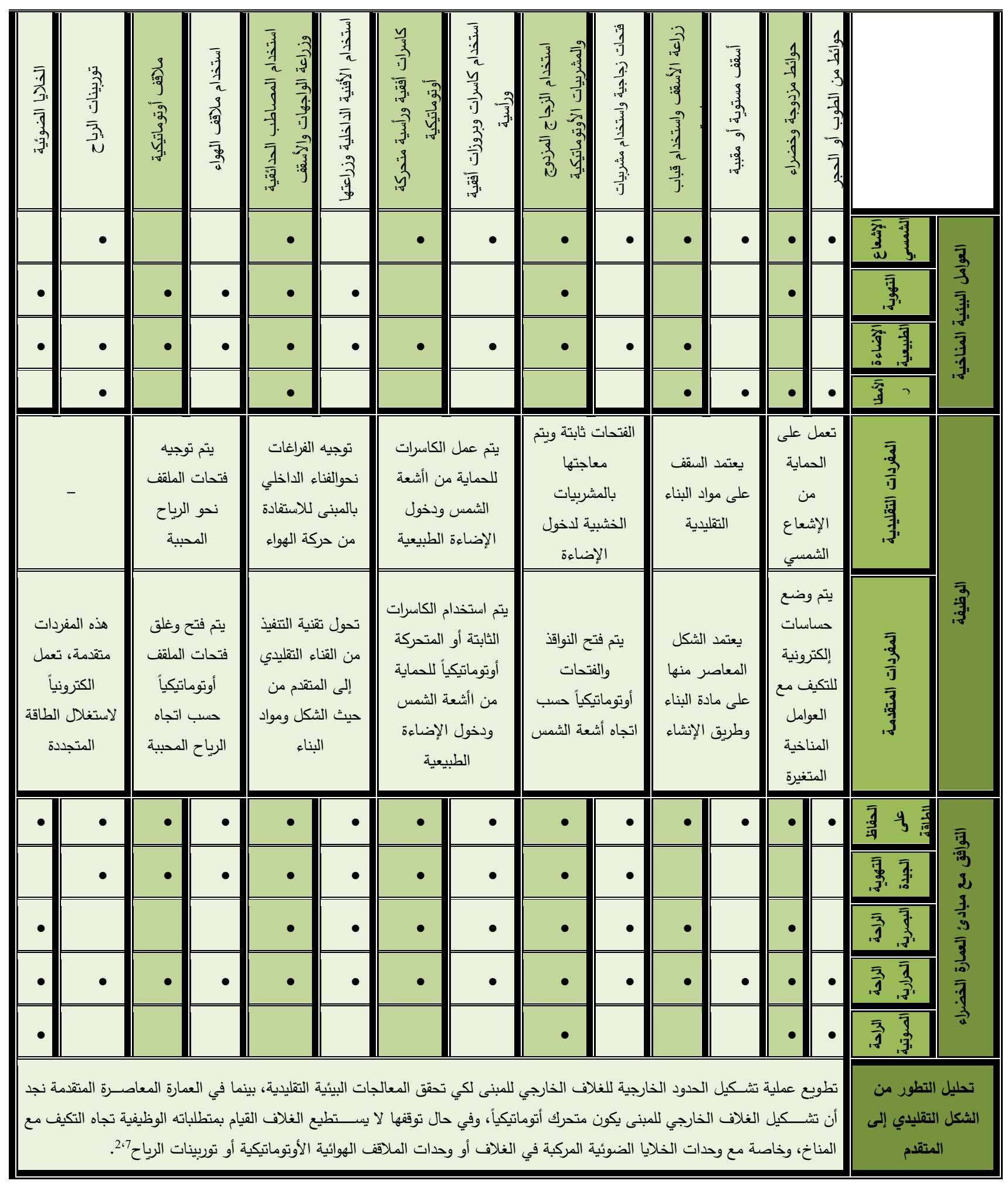

توصـل البحث إلى مجموعة من النتائج العامة والخاصــــ

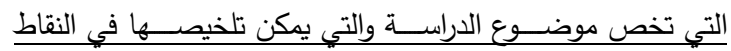

التالية:-

1. تعتبر العمارة الخضــــاء Green Architecture أحد أهم

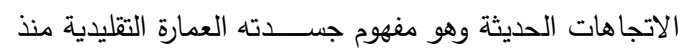

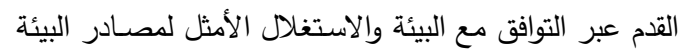

ومن خلال الجدول السابق (3) نستنتج أن هناك اختلاف

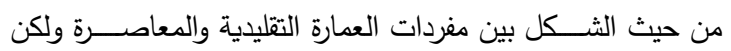
يتفقان في الوظيفة والمبادئ المحققة للعمارة الخضراء.

7- النتائج والتوصيات:

1-7-7 النتائج البشية:- 
10.قدمـت العمـارة التقليديـة بمفرداتها نموذجـاً جيداً في تحقيق الكفاءة الحراريـة والتهويـة الطبيعيـة،وهذا يتوافق مع مبادئ العمارة الخضراء. 11. المرتكزات البيئية التي قام عليها تصــــميم المغردات التقليدية، ومع اســتعراض نماذج مختلفة للعمارة المعاصـــرة المتأثرة

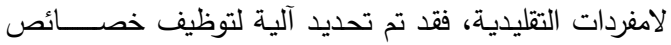

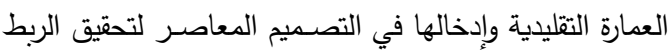
بين التقليدية والمعاصـــرة وتحقيق تصــــيم متوافقة مع البيئة المحلية.

-2-7

1. ضـــرورة التأكيدعلى أهمية التعامل مع معطيات البيئة واتخاذ

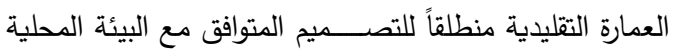

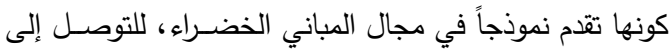
ايجاد عمارة خضراء معاصرة تتتمي الي البيئة التقليدية المحلية فى مصر الجا 2. محاولة الاسـتفادة من اسـتخدام المفردات التقليدية والمعالجات البيئية التي اعتمد عليها المصم، حتى يمكن استعمالها بصورة التصنية

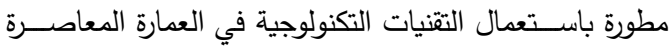
للوصــول لعمارة معاصــرة متوافقة مع البيئة المحلية في إطار من الأصالة المعاصرة. 3. بحث أســـاليب متطورة لاســــــدام أنواع ملاءمه من الزجاج العـازل للنوافذ والفتحـات، وتعزيز دور التهويـة والاضــــــاءة الطبيعية وما يتضمنه ذلك من التظليل والتدفئة.

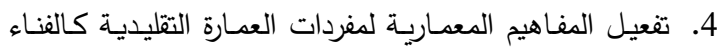
وملقف الهواء والمشربيات وعناصر التظليل والتحكم بالاضـاءة

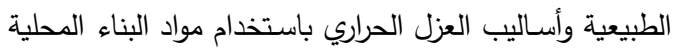
والتقنيات الطبيعية التي كانت تستخدم لترطيب الهواء وتبريده، وتوظيفها في المباني المعاصـرة والاستعانة بالدراسـات العلمية

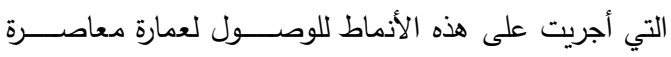
خضراء تلاءم البيئة المحلية. 5. ضرورة أن يراعي المصممين في التخصصات المختلفة إدماج أنظمـة إدارة الطـاقـة بـالمباني للتحكم في تثــــيـل الأجهزة

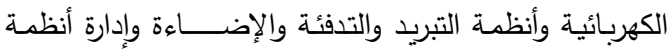
الطاقة المتجددة.

6. الاستفادة منملقف الهواء بفتح نوافذ علوية صغيرة لتأمين تهوية

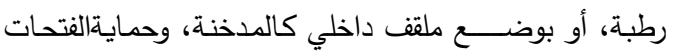
بكاسـرات الثـمس المناسـبة ويفضـل أن تكوف متحركة، إلى دانى جانباسـتخدام النباتات في الأسـطح، وهذا ما ترســـه العمارة

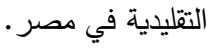

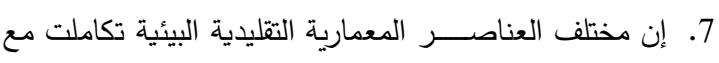
بعضـها البعض لحل المشـكلات المناخية من خلال الاعتماد

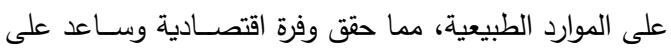

الطبيعيـة، بينمـا في الحـاضــــر يتجـهـ البعض لاســـتغلال

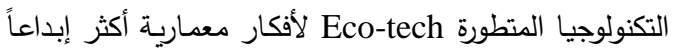
وتقدماً في استغلال المواد وطرق تصنيعها واستعمالها.

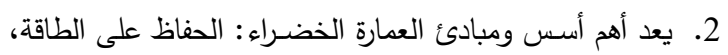

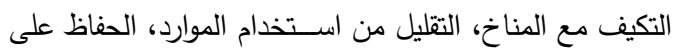

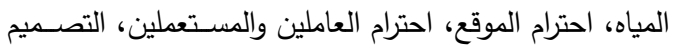
الثامل، وهي ما رسخته العمارة التقليدية في معالجات مبانيها. 3. تركز العديد من الدراسـات كما في مبنى معهد مصدر والمعهد

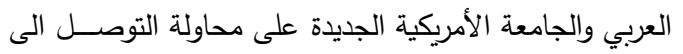
عمارة خضراء معاصرة تتنتي إلي البيئة العربية وتراثها العريق

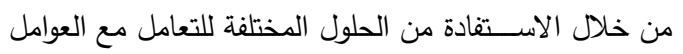
المناخية. 4. إهتمت العديد من الدراسـات السـابقة بتفعيل المفاهيم المعمارية

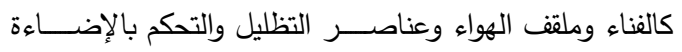
الطبيعية وأسـاليب العزل الحراري باستخدام مواد البناء المحلية والتتنيات الطبيعية التي كانت تســتخدم لترطيب الهواء وتبريده والاستعانة بالدراسات العلمية التي أجريت على هذه الأنماط.

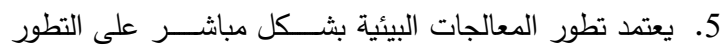

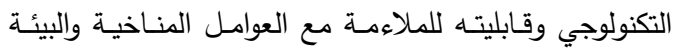
المحلية. 6. تعتبر المعالجات التقليدية هي أصلـ فكرة عمل معظم التقنيات الحديثة، حيث الثكل التقليدي للمعالجات هو استجابة طبيعية

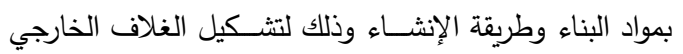

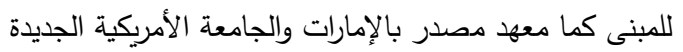
بكصــر ، بينما المعالجات المتقدمة هي اســـتجابة ديناميكية تكنولوجية كما في المعهد العربي بباريس للظروف المناخية ومشروع ذي جيت بمصر ·

7. إتسـت معظم المعالجات ذات التكنولوجيا الخضـراء باستخدام الآليات والتتنيات التي تعمل على خفض اســـــلاكل الطاقة وذلك باستخدام الألواح الثمسية والسطوح الألومنيومية العاكسة واستخدام الكاسـرات الرأسية والأفقية المتحركة كما في المعهد العربي بباريس، مع توظيف استخدام الطاقة الثـمسـية وطاقة الرياح من خلال الأنظمة الكهروضوئية مما يعمل على خفض لئل استهلاك الطاقة. 8. العناصـر التي نجحت في تحقيق مسـتويات جيدة من التهوية والتبريد والتدفئة اعتمدت علي مفردات المعالجات التقليديـة

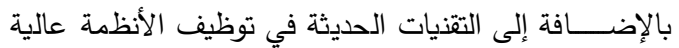
الكفاءة وأنظمة التحكم فيالمباني لتقليل الفاقد في أحمال التبريد والتدفئة والتحكم الكلي بها. 9. أكثر الأنظمة المستخدمة في توليد الطاقة هي الخلايا الضوئية بأنواعها المختلفة بالواجهات الزجاجية وتتتوع أماكن تواجدها بالمباني بين الواجهات الأمامية والأسقف المستوية والمائلة. 
environmental design treatments in the design process stages in hot - dry areas - University of Technology - Department of Architecture University of Baghdad - 2016.

[8] Muhammad Saif Al-Nasr Ahmed Methodology for rationalizing energy consumption in buildings using modern technologies Department of Architectural Engineering at the Faculty of Engineering at Matareya, Helwan University - 2017.

[9] Al-Salqini Kindergarten - Solar Traditional Architecture: How Much Scope to Improve Building Energy Consumption - Al Baath University Journal - Volume 39, Issue 35, 2017

[10] Eslam Mohamed Mahmoud MoraekipSustainable Architecture Between Theory and Application in Egypt- Master Faculty of Engineering - Mattaria- Helwan University- 2010

[11] Sara Abd El Baki Mahmoud- Environmental Solutions as Main Approach to Sustainable Neighborhood- Master of Science in ArchitectureFaculty of Engineering-Ain Shams University2014

[12] Simon Roberts \& Nicolo Guariento, "Building integrated photovoltaics", Birkhauser Verlag AG, 2009

[13] Nermine Abdel Gelil Mohamed- Traditional Residential Architecture in Cairo from a Green Architecture Perspective- Department of Architecture, Faculty of Engineering, October University for Modern Sciences and Arts (MSA University), 6th of October City, Egypt 2014.

[14] Wael Ahmed Shaaban Abo Neama- Applying Sustainability Principles on Architectural Design Concepts in Egypt to Enhance Building Performance- Lecturer in Architectural department, Faculty of Fine Arts, Helwan University, Zamalek, Cairo, Egypt- 2013.

[15] http://www.aucegypt.edu, Accessed $10 \backslash 10 \backslash 2018$.

[16] AIA, "Top Ten Projects: Research Support Facility", 2014 , Site:http://www.aiatopten.org/node/103, accessed 10-7-2018.

[17] www.google.com : (DIFC) DIFC LIGHTHOUSE TOWER10/11/2018.

[18] WWW.Green-archeticture.com- 12/10/2017.

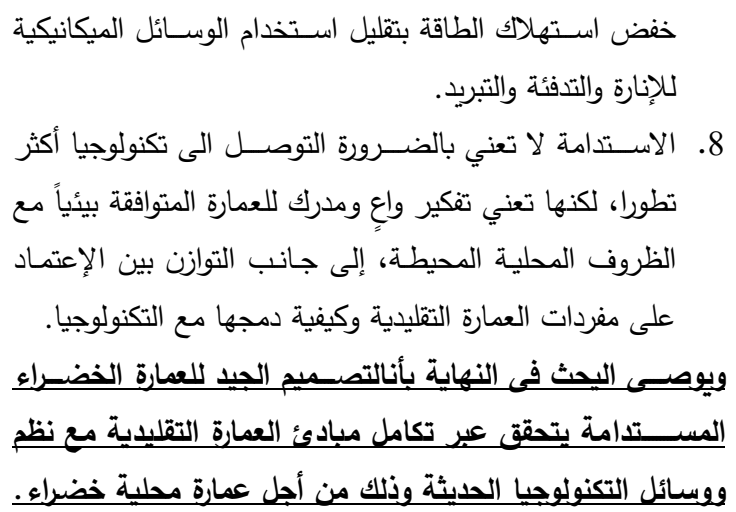

المراجح:

[1] Safa Muhammad Al-Saeed - Design Treatments for Zero Energy Skyscrapers in a Hot Climate - MSc - 2014.

[2] Mona Muhammad Hosni Ajur - Environmental treatments in green architecture between traditional and local advanced technology and their impact on shaping the building envelope - Engineering Journal - Faculty of Engineering at Matareya Helwan University - 2013.

[3] Hassan Ahmed Hassan Youssef - The role of green buildings in energy conservation Department of Architecture - Institute of Aeronautical Engineering and Technology - 2017.

[4] Dima Omar Qasim - Sustainability in Traditional Architecture and its Applications in Contemporary Architecture - Master Thesis College of Architecture - Engineering Sciences Series Volume (36) Issue (3) 2014 - Tishreen University.

[5] Ghada Kamouneh, Lenore Saad Complementarity of the building's work as a system employed for advanced technology in facing external climatic conditions - Department of Architecture - University of Baghdad - Engineering Journal, Issue 17, 2011.

[6] Naama Hassan El-Sayed Omar - Monitoring and recording of the application of computer technologies and their role in developing future architecture (case study on smart architecture buildings) - Master Thesis - Faculty of Engineering - Cairo University - 2013.

[7] Yunus Mahmoud Muhammad Salim - Sri Zakaria Yahya Mahmoud - employing 